\title{
SUR UN BRAGA DU PARAGUAY
}

\author{
Par Th. MONOD
}

M. Guillermo Schouten a bien voulu me communiquer un couple d'Isopodes recueilli dans la région d'Asunción, au bord du Riacho Karakara, lac en communication avec le Rio Paraguay.

La femelle se rapproche tant de l'exemplaire figuré par Schiœdte et Meinert (Symbolæ ad monographiam Cymothoarum, 1884, pp. 419-420, pl. XVIII, fig. 17-18), sous le nom de Braga patagonica que je rapporte à cette espèce le couple d'Asunción.

Le mâle de $B$. patagonica n'ayant pas encore été signalé (1), je profite de l'occasion pour le figurer.

Les mâles de Braga sont probablement très semblables pour les différentes espèces du genre, comme c'est le cas pour les Codonophilus, les Cymothoa, etc., et il est bien peu vraisemblable que les espèces puissent être distinguées sur des exemplaires mâles.

Les espèces actuellement connues du genre Braga sont, à ma connaissance, les suivantes :

1. Braga nasuta Schioedte et Meinert (Symbolæ..., 1881, pp. 93-94, pl. VII, fig. 8-9). - Hab. Côtes du Brésil, sans localité exacte (mâle inconnu).

2. Braga cichlæ Schioedte et Meinert (Symbolæ..., 1881, pp. 9496, pl. VII, fig. 10-11). - Hab. José Apu, Brésil, sur la langue de Cichla sp. Cette espèce a donc été capturée dans l'eau douce, alors que Richardson (Bull. Mus., Paris, 1911, p. 96) considère son $B$. fluviatilis comme le premier Braga dulcaquicole connu (mâle inconnu).

3. Braga brasiliensis Schioedte et Meinert (Symbolæ..., 1881, pp. 9697, pl. VII, fig. 12-13). - Hab. Côtes du Brésil, sans localité exacte (mâle inconnu).

(1) Richardson (Bull. Mus. Paris, 1911, p. 96) affirme que le mâle de B. patagonica a été « découvert, mais non décrit ». Il m'a été impossible de découvrir dans la littérature la mention de ce mâle; les descripteurs, en tous les cas, ne font pas la plus légère allusion à l'existence d'un autre spécimen que le type, une "virgo adolescens » appartenant au Musée de Copenhague, exemplaire sec et mal conservé, « Specimen exsiccatum et male conservatum..... »

Annales de Parasitologie, T. IX, $\mathrm{N}^{\circ} 4 .-1^{\text {er }}$ juillet 1931 , p. 363-365. 
4. Braga patagonica Schioedte et Meinert (Symbolæ..., 1884, pp. 419-420, pl. XVIII, fig. 17-18). - Hab. Côtes de Patagonie, près du Rio Negro ; Rio Paraguay, dans les environs d'Asunción (Schouten, coll. 1929).

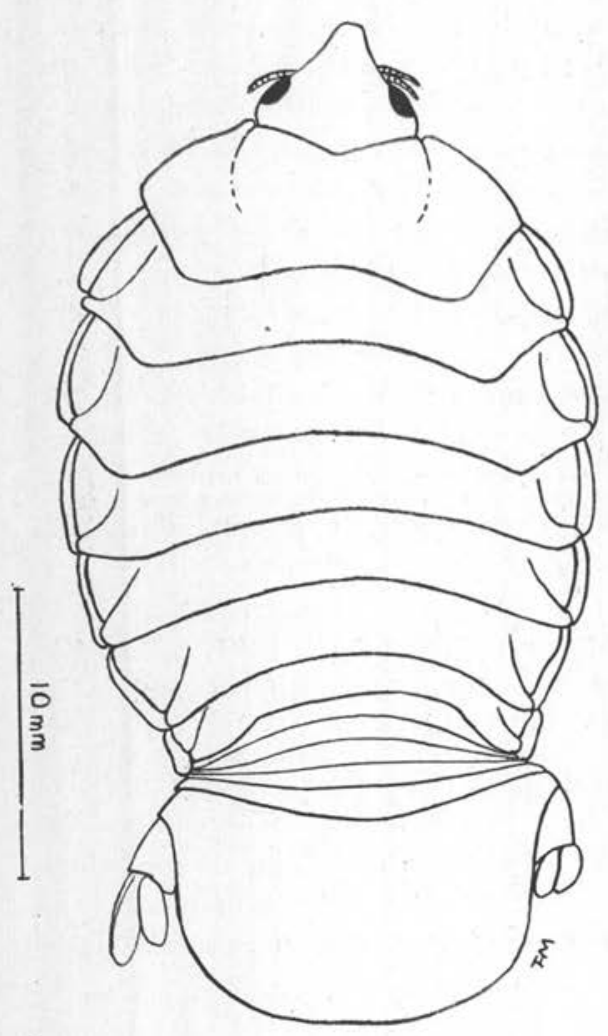

FIg. 1. - Braga patagonica, femelle.

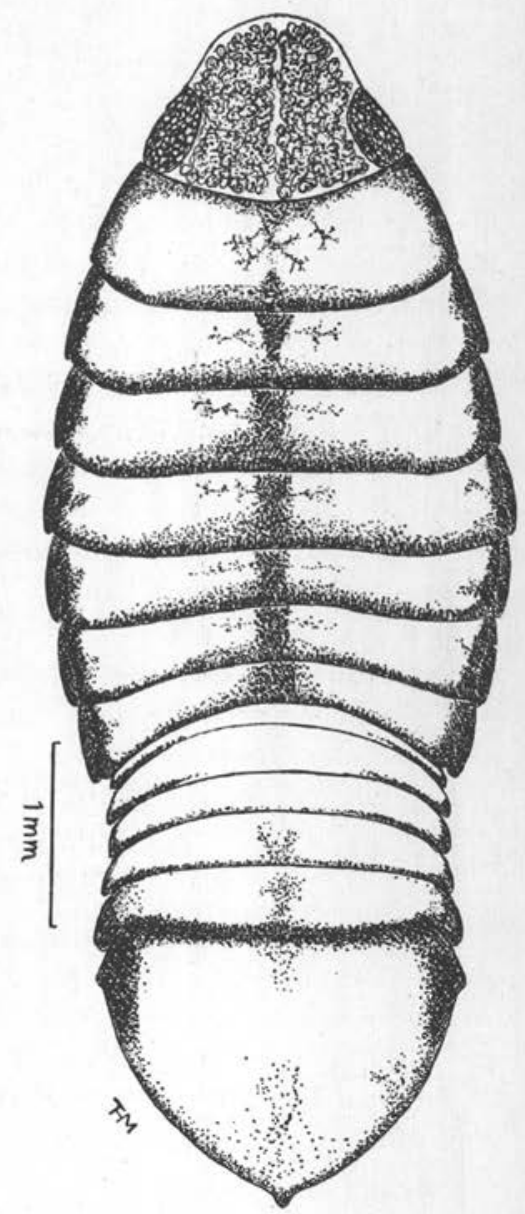

FIG. 2. - Braga patagonica, mâle.

5. Braga occidentalis Boone (Proc. U. S. nat. Mus., 54, 1918, pp. 595-596, pl. 91, fig. 1). - Hab. Côte de Californie, sans localité exacte (mâle inconnu).

A titre de species inquirenda, il faut signaler enfin Braga fluviatilis Richardson (Bull. Mus. Paris, 1911, pp. 95-96, fig. 1-2) décrit 


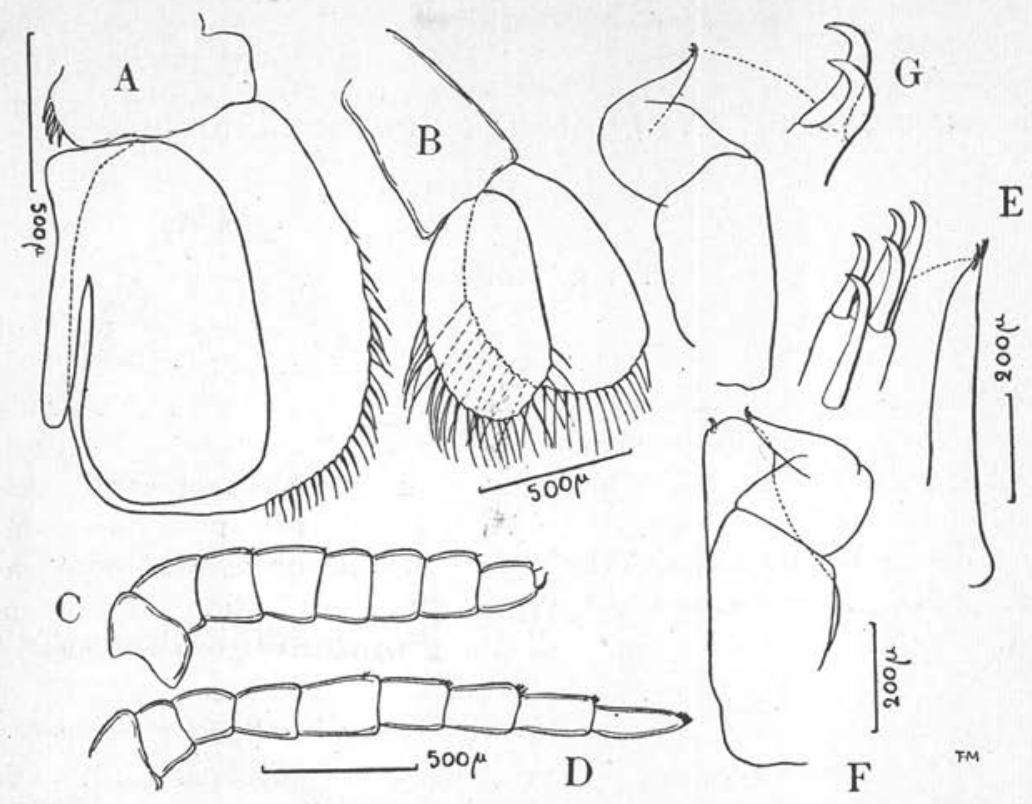

FIg. 3. - Braga patagonica, mâle. A, pléopode; B, uropode droit, face inférieure ; $\mathrm{C}$, antennule; $\mathrm{D}$, antenne; $\mathrm{E}$, maxillule et maxillipède; $\mathrm{F}$, maxille et maxillipède; G, maxillipède.

sur un mâle unique trouvé dans la bouche d'un Silure, à Villa Lutecia, environs de San-Ignacio, Haut-Parana. Tant que des femelles topotypiques n'auront pas été examinées, il ne saurait être prouvé que $B$. fluviatilis n'est pas le mâle d'une forme déjà connue.

Museum national d'Histoire naturelle

Laboratoire de M. le Professeur A. Gruvel 